\title{
PEST-containing nuclear protein mediates the proliferation, migration, and invasion of human neuroblastoma cells through MAPK and $\mathrm{PI} 3 \mathrm{~K} / \mathrm{AKT} / \mathrm{mTOR}$ signaling pathways
}

Dong-Dong $\mathrm{Wu}^{1 \dagger}$, Ying-Ran Gao ${ }^{1 \dagger}$, Tao $\mathrm{Li}^{1 \dagger}$, Da-Yong Wang ${ }^{1}$, Dan Lu', Shi-Yu Liu', Ya Hong ${ }^{1}$, Hui-Bin Ning ${ }^{2}$, Jun-Ping Liu' ${ }^{2}$, Jia Shang ${ }^{2}$, Jun-Feng Shi ${ }^{4}$, Jian-She Wei, ${ }^{3,4^{*}}$ and Xin-Ying $\mathrm{Ji}^{1,2^{*}}$

\begin{abstract}
Background: PEST-containing nuclear protein (PCNP), a novel nuclear protein, is involved in cell proliferation and tumorigenesis. However, the precise mechanism of action of PCNP in the process of tumor growth has not yet been fully elucidated.

Methods: ShRNA knockdown and overexpression of PCNP were performed in human neuroblastoma cells. Tumorigenic and metastatic effects of PCNP were examined by tumor growth, migration, and invasion assays in vitro, as well as xenograft tumor assay in vivo.

Results: PCNP over-expression decreased the proliferation, migration, and invasion of human neuroblastoma cells and down-regulation of PCNP showed reverse effects. PCNP over-expression increased protein expressions of cleaved caspase-3, cleaved caspase-8, cleaved caspase-9, and cleaved poly adenosine diphosphate-ribose polymerase, as well as ratios of B-cell lymphoma-2 (Bcl-2)-associated X protein/Bcl-2 and Bcl-2-associated death promoter/B-cell lymphoma-extra large in human neuroblastoma cells, however PCNP knockdown exhibited reverse trends. PCNP overexpression increased phosphorylations of extracellular signal-regulated protein kinase 1/2, p38, c-Jun N-terminal kinase, as well as decreased phosphorylations of phosphatidylinositol 3-kinase (PI3K), Akt, and mammalian target of rapamycin (mTOR), nevertheless PCNP knockdown exhibited opposite effects. Furthermore, PCNP over-expression significantly reduced the growth of human neuroblastoma xenograft tumors by down-regulating angiogenesis, whereas PCNP knockdown markedly promoted the growth of human neuroblastoma xenograft tumors through up-regulation of angiogenesis.
\end{abstract}

Conclusions: PCNP mediates the proliferation, migration, and invasion of human neuroblastoma cells through mitogen-activated protein kinase and PI3K/AKT/mTOR signaling pathways, implying that PCNP is a therapeutic target for patients with neuroblastoma.

Keywords: PEST-containing nuclear protein, Neuroblastoma, Angiogenesis, Apoptosis, Signaling pathway

\footnotetext{
* Correspondence: jswei@henu.edu.cn; xinying_ji@henu.edu.cn

${ }^{\dagger}$ Equal contributors

${ }^{3}$ Brain Research Laboratory, College of Life Sciences, Henan University,

Kaifeng 475004, Henan, China

'School of Basic Medical Sciences, Henan University College of Medicine,

Kaifeng 475004, Henan, China

Full list of author information is available at the end of the article
}

(c) The Author(s). 2018 Open Access This article is distributed under the terms of the Creative Commons Attribution 4.0 International License (http://creativecommons.org/licenses/by/4.0/), which permits unrestricted use, distribution, and reproduction in any medium, provided you give appropriate credit to the original author(s) and the source, provide a link to the Creative Commons license, and indicate if changes were made. The Creative Commons Public Domain Dedication waiver (http://creativecommons.org/publicdomain/zero/1.0/) applies to the data made available in this article, unless otherwise stated. 


\section{Background}

Neuroblastoma, a pediatric cancer of the developing sympathetic nervous system, is one of the most common solid tumors in infancy and early childhood [1-3]. The tumor emerges in tissues of the sympathetic nervous system, typically in the paraspinal ganglia or adrenal medulla, and thus can present as mass lesions in the chest, neck, pelvis, and abdomen [4]. The prognosis is highly variable and is associated with a number of parameters including tumor stage, age at diagnosis, and grade of differentiation of the tumor $[5,6]$. Although the survival of children with neuroblastoma has significantly improved during recent years, patients with advanced-stage disease still show a poor prognosis, despite intensive and advanced treatments, with overall survival probabilities of less than 40\% [7-9]. Therefore, it is urgent to clarify the molecular and genetic properties of neuroblastoma that will greatly improve the therapeutic effect of this complex heterogeneous disease $[5,10]$.

The PEST motif is a peptide sequence which is rich in proline $(\mathrm{P})$, glutamic acid $(\mathrm{E})$, serine $(\mathrm{S})$, and threonine (T) [11-13]. It is well known that the PEST sequence functions as a proteolytic signal to target proteins for degradation via the proteasome pathway or calpain proteolysis $[11,14,15]$. The PEST sequence is considered the unstructured region in a number of protein sequences, possibly serving as a phosphodegron for the recruitment of F-box-containing ubiquitin E3 ligases that result in ubiquitination and degradation [16, 17]. A novel PEST-containing nuclear protein (PCNP) has been identified in the nucleus through database mining. Np95/ICBP90-like RING finger protein (NIRF) is a nuclear protein with a ubiquitin-like domain, a YDG/SRA domain, a PHD finger, and a RING finger. PCNP could interact with NIRF and modulate the transcriptional activity of NIRF [18]. PCNP and NIRF may be involved in the signaling pathway concerned with cell cycle regulation and/or genome stability [19]. In addition, it has been shown that PCNP mRNA can be detected in many types of cancer cells, such as HT-1080 fibrosarcoma cells, HepG2 hepatoma cells, and U-937 myeloid leukemia cells, indicating that PCNP might play an important role in cell proliferation and tumorigenesis $[18,19]$. However, the expression level of PCNP in neuroblastoma cells is unknown, and the effect of PCNP on the growth of neuroblastoma cells has not yet been elucidated.

In the present study, we investigated the effects and mechanisms of PCNP on the proliferation, migration, and invasion of human neuroblastoma cells. We further examined the effects of PCNP on tumor growth and angiogenesis in nude mice xenografted with human neuroblastoma.

\section{Methods}

\section{Cell culture}

Human neuroblastoma cell lines SH-SY5Y and SK-N-SH were purchased from CoBioer Biosciences Co., Ltd. (Nanjing, Jiangsu, China) and cultured in RPMI1640 medium supplemented with $10 \%$ fetal bovine serum (FBS), $100 \mathrm{U} / \mathrm{ml}$ penicillin, and $100 \mu \mathrm{g} / \mathrm{ml}$ streptomycin. Cells were grown in an incubator with a humidified atmosphere of $95 \%$ air and $5 \% \mathrm{CO}_{2}$ at $37{ }^{\circ} \mathrm{C}$.

\section{Over-expression and knockdown of PCNP}

Human PCNP complementary deoxyribonucleic acid (cDNA) (NM_020357) was sub-cloned into the Xho I and Kpn I restrictive sites of GV230 (Genechem, Shanghai, China), validated by sequencing and transfected into tumor cells with Lipofectamine 3000 Transfection Reagent (Life Technologies, Carlsbad, CA, USA). The empty vector (Mock group) or GV230-PCNP construct (PCNP group) was transfected into tumor cells, and stable cell lines were screened by administration of G418 (Solarbio, Shanghai, China). The oligonucleotides encoding short hairpin ribonucleic acid (shRNA) specific for PCNP and their scramble sequences were sub-cloned into the Age I and EcoR 1 restrictive sites of GV248 (Genechem, Shanghai, China). The PCNP shRNA (sh-PCNP group) and scramble shRNA (sh-Scb group) were verified by DNA sequencing and transfected into tumor cells with Lipofectamine 3000 Transfection Reagent. Stable tumor cell lines transfected with shRNAs were screened by administration of puromycin (Solarbio, Shanghai, China). The untransfected tumor cells were used as controls. Seventy-two hours post-transfection, the localization of PCNP within tumor cells was detected under a fluorescent microscope (Eclipse Ti, Nikon, Melville, NY, USA).

\section{Reverse transcription-polymerase chain reaction (RT-PCR)}

Seventy-two hours post-transfection, total RNA was isolated from the cells using TRIzol reagent, treated with DNase I, and purified using an RNA clean-up kit (Cwbiotech, Beijing, China). Total RNA (1 $\mu \mathrm{g})$ was applied for cDNA synthesis using a cDNA reverse transcription kit (Cwbiotech, Beijing, China). Primers were designed according to the primer design principles with Primer Premier 5.0 (Premier Biosoft, Palo Alto, CA, USA): PCNP, forward 5'ATAGGATCC AAAATGGCGGACGGGAAGGCG-3' and reverse 5' CCGAAGCTTTTAATTGTCTTGGTCATGGAC-3'; and glyceraldehyde-3-phosphate dehydrogenase (GAPDH), forward 5'TATGACAACGAATTTGGCTACAG-3' and reverse 5'-GATGGTACATGACAAGGTGC-3'. The reactions were performed in a total volume of $20 \mu \mathrm{l}$ using the following thermal cycling parameters: $95{ }^{\circ} \mathrm{C}$ for $10 \mathrm{~min}$, 40 cycles of $95{ }^{\circ} \mathrm{C}$ for $15 \mathrm{~s}, 60{ }^{\circ} \mathrm{C}$ for $60 \mathrm{~s}$, and $72{ }^{\circ} \mathrm{C}$ for $1 \mathrm{~min}$. The results were normalized to the level of GAPDH. 


\section{Cell proliferation and viability assays}

The 5-ethynyl-2'-deoxyuridine (EdU) incorporation assay was performed using the Cell-Light EdU Apollo 567 In Vitro Imaging Kit (RiboBio, Guangzhou, Guangdong, China). After incubation with $10 \mathrm{mM}$ EdU for $2 \mathrm{~h}, \mathrm{SH}-$ SY5Y and SK-N-SH cells were fixed with $4 \%$ paraformaldehyde, permeabilized with $0.3 \%$ Triton X-100, and stained with fluorescent dyes. 4', 6-diamidino-2-phenylindole (DAPI) was used to stain the cell nuclei (blue) at a concentration of $5 \mathrm{mg} / \mathrm{ml}$ at room temperature for $10 \mathrm{~min}$. Cells were observed under a fluorescent microscope (Eclipse Ti, Nikon, Melville, NY, USA). Cell proliferation rate $(\%)=($ EdU-positive cells $) /($ total number of cells) $\times 100$ [20]. The cell viability was detected using the CellTiter 96 AQueous One Solution Cell Proliferation Assay kit (MTS; Promega, Madison, WI, USA) according to the manufacturer's protocols.

\section{Colony formation assay}

Cells $\left(4 \times 10^{2}\right.$ per well) were seeded in 6-well plates and cultivated in culture medium at $37{ }^{\circ} \mathrm{C}$ for a week. At that point, colonies were washed with phosphate-buffered saline (PBS) buffer for three times before subjected to cell fixation using $1 \mathrm{ml}$ of methanol at room temperature for $15 \mathrm{~min}$. Then, $1 \mathrm{ml}$ of crystal violet was added into each well and incubated for $30 \mathrm{~min}$ at room temperature. Plates were gently washed with water and air-dried at room temperature. Finally, the 6-well plate was scanned for colony counting and analysis.

\section{Wound healing assay}

Confluent cells were scratched with a sterile micropipette tip and subsequently washed twice with PBS. The migration distance was photographed under an Olympus CKX41 microscope and then measured using Image J software (National Institute for Health, Bethesda, MD, USA). The migration rate (MR) was calculated as MR $(\%)=[(\mathrm{A}-\mathrm{B}) / \mathrm{A}] \times 100$, where $\mathrm{A}$ is the width at $0 \mathrm{~h}$, and $B$ is the width at $24 \mathrm{~h}$.

\section{Soft agar assay}

Cells were suspended in $0.6 \%$ agarose and medium supplemented with $10 \% \mathrm{FBS}$, and the mixture was seeded in 6 -well plates containing a basal layer of $1.2 \%$ agarose at $1 \times 10^{4}$ cells/well. The medium was replaced twice per week. After 2 weeks of routine culture, colonies were photographed under an Olympus CKX41 microscope. Viable colonies larger than $0.1 \mathrm{~mm}$ in diameter were counted.

\section{Migration and invasion assays}

For migration and invasion assays, $1 \times 10^{5}$ cells in serum-free medium were seeded into the upper chamber uncoated or coated with Matrigel (BD Biosciences, San
Jose, CA, USA). $500 \mu \mathrm{l}$ corresponding medium containing $10 \%$ FBS was added to the lower chamber. After incubation for $24 \mathrm{~h}$, remaining cells were scrubbed off with cotton swabs, while cells on the bottom surface of the membrane were fixed with $4 \%$ paraformaldehyde and stained with $0.1 \%$ crystal violet. The cell number was counted using a Zeiss Axioskop 2 plus microscope (Carl Zeiss, Thornwood, NY, USA).

\section{TdT-mediated dUTP-biotin nick end labeling (TUNEL) assay}

TUNEL assay was conducted using an In Situ Cell Death Detection Kit (Beyotime Biotechnology, Shanghai, China) according to the manufacturer's protocols. Cells were observed under a fluorescent microscope (Eclipse Ti, Nikon, Melville, NY, USA). The percentage of TUNEL-positive cells was calculated using Image J software.

\section{Western blotting}

Seventy-two hours post-transfection, total protein was extracted from SH-SY5Y and SK-N-SH cells. Western blotting was performed to detect the expression of target proteins. The primary antibodies, including antiextracellular signal-regulated protein kinase 1/2 (ERK1/ 2), anti-phospho (p)-ERK1/2 (Thr202/Tyr204), anti-cJun N-terminal kinase (JNK), anti-p-JNK (Thr183/ Tyr185), anti-p38, anti-p-p38 (Thr180/Tyr182), antiphosphatidylinositol 3-kinase (PI3K), anti-p-PI3K (Tyr458/Tyr199), anti-Akt, anti-p-Akt (Ser473), antimammalian target of rapamycin (mTOR), and anti-pmTOR (Ser2448) antibodies were purchased from Cell Signaling Technology (CST, Danvers, MA, USA). AntiPCNP, Anti-B-cell lymphoma-2 (Bcl-2), anti-Bcl-2-associated $\mathrm{X}$ protein (Bax), anti-B-cell lymphoma-extra large (Bcl-xl), anti-Bcl-xl/Bcl-2-associated death promoter (Bad), anti-cleaved caspase-3, anti-cleaved caspase-8, anti-cleaved caspase-9, anti-Cleaved poly adenosine diphosphate-ribose polymerase (PARP), and antiGAPDH antibodies were purchased from ProteinTech (Chicago, IL, USA). The horseradish peroxidaseconjugated secondary antibody was purchased from Cell Signaling Technology. The results were normalized to the level of GAPDH. The reaction was visualized using an enhanced chemiluminescence system (Thermo Fisher Scientific, Rockford, IL, USA). The bands were semiquantified with Image J software.

\section{Animal study}

Animal experiments were approved by the Committee of Medical Ethics and Welfare for Experimental Animals of Henan University School of Medicine (HUSOM-2017-196) in compliance with the Experimental Animal Regulations formulated by the National Science and Technology Commission, China. Animal studies were conducted as 
previously described with slight modifications [21]. Thirty 4-week-old male BALB/C nude mice ( $n=6$ per group) were obtained from Beijing HFK Bioscience Co., Ltd. (Certificate No. SCXK (Jing) 2014-0004, Beijing, China). SH-SY5Y and SK-N-SH cells $\left(1 \times 10^{7}\right.$ cells in $200 \mu \mathrm{l}$ PBS $)$ with overexpression and knockdown of PCNP were implanted by subcutaneous injection into the right flanks of mice. The mice were weighed and the tumor volumes were measured daily during the experiment. The tumor volumes were calculated as volume $=\mathrm{L} \times \mathrm{W}^{2} / 2$, where $\mathrm{L}$ is the longest dimension parallel to the skin surface and $\mathrm{W}$ is the dimension perpendicular to $\mathrm{L}$ and parallel to the surface [22]. Then the tumor volume doubling time (TVDT) was calculated. TVDT $=\left(\mathrm{T}-\mathrm{T}_{0}\right) \times \log 2 / \log (\mathrm{V} 2 / \mathrm{V} 1)$, where $(\mathrm{T}$ $-\mathrm{T}_{0}$ ) represents the time interval and V2 and V1 indicate the volumes of tumor at the two measurement times [23]. At the end of the experiment, mice were sacrificed and tumors were excised and weighted to evaluate the inhibition rate (IR). The IR of tumor growth was calculated as IR $(\%)=[(\mathrm{A}-\mathrm{B}) / \mathrm{A}] \times 100$, where $\mathrm{A}$ is the average tumor weight of the control group, and $B$ is that of the treatment group [21].

\section{Hematoxylin and eosin (HE) staining}

After sacrifice, a necropsy examination was immediately performed. Tumor samples were fixed in 10\% neutral buffered formalin, embedded in paraffin, sectioned at $5 \mu \mathrm{m}$ thickness, and processed according to the $\mathrm{HE}$ staining protocols. Tumor tissues were observed using a Zeiss Axioskop 2 plus microscope.

\section{Immunohistochemistry (IHC) and evaluation}

Tumor tissues were stained with anti-Ki67 antibody (CST, Danvers, MA, USA), followed by incubation with secondary antibody. Ki67-positive tumor cells were photographed using a Zeiss Axioskop 2 plus microscope and the proliferation index (PI) was determined by the number of Ki67 positive cells among the total number of counted tumor cells [24]. Cluster of differentiation 31 (CD31) has been considered an ideal biomarker for vascular endothelial cells, and its immunostaining density is represented by the tumor microvessel density (MVD) [25]. To determine the tumor MVD, tumor tissues were stained by IHC using CD31 antibody (CST, Danvers, MA, USA). Stained vessels with a clearly defined lumen or well-defined linear vessel shape were observed using a Zeiss Axioskop 2 plus microscope and counted from the representative tumor zone, and the mean value was regarded as MVD.

\section{Statistical analysis}

Data are presented as means \pm standard error of the mean. The differences between multiple groups were analyzed by one-way analysis of variance using SPSS 17.0 software, followed by Tukey's test. A $P$ value of less than 0.05 was considered to be statistically significant.

\section{Results \\ Over-expression and down-regulation of PCNP in human neuroblastoma cells}

To investigate the hypothesis that PCNP could influence the growth process of human neuroblastoma cells, PCNP over-expression and knockdown experiments were performed. Transfection of PCNP into SH-SY5Y and SK-N-SH cells resulted in increased nuclear expression of PCNP and transfection of sh-PCNP reduced the nuclear expression of PCNP in SH-SY5Y and SK-N-SH cells (Fig. 1a). In addition, mRNA and protein levels of PCNP showed similar trends (Fig. 1b-d). These results indicate that PCNP over-expression and knockdown experiments have been successfully performed in human neuroblastoma cells.

\section{PCNP regulates the growth, migration, and invasion of human neuroblastoma cells}

As shown in Fig. 2a and b, PCNP over-expression decreased the proliferation of SH-SY5Y and SK-N-SH cells, when compared to the Mock group. In contrast, PCNP knockdown showed opposite effect compared with the sh-Scb group. PCNP showed similar effect on the viability of human neuroblastoma cells (Fig. 2c). Furthermore, over-expression of PCNP reduced the colony formation in SH-SY5Y and SK-N-SH cells and PCNP knockdown markedly increased the number of colonies (Fig. 2d and e). In scratch migration assay, PCNP overexpression attenuated the migration capabilities of $\mathrm{SH}$ SY5Y and SK-N-SH cells and PCNP knockdown exhibited reverse trends (Fig. $3 a$ and b). In soft agar assay, PCNP over-expression attenuated the anchorageindependent growth of SH-SY5Y and SK-N-SH cells and down-regulation of PCNP showed reverse effects (Fig. $3 \mathrm{c}$ and $\mathrm{d}$ ). Transwell analysis showed that neuroblastoma cells transfected with PCNP presented impaired migration and invasion capacities, while the sh-Scb group showed reverse trends (Fig. $3 \mathrm{e}-\mathrm{h}$ ). These results together suggest that PCNP is involved in the growth, migration, and invasion of human neuroblastoma cells.

PCNP modulates apoptosis of human neuroblastoma cells As shown in Fig. 4a and b, the apoptotic index increased in the PCNP group compared with the Mock group and decreased in the sh-PCNP group compared with the shScb group. The protein expression levels of cleaved caspase-3, 8, 9, and cleaved PARP in human neuroblastoma cells showed similar trends (Fig. 4c-e). The ratio between Bax and Bcl-2 and the ratio between Bad and $\mathrm{Bcl}-\mathrm{xl}$ have been considered important factors in the regulation of apoptosis. In mammalian cells, increased 


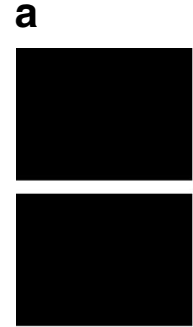

Control
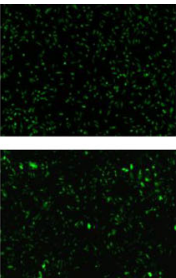

Mock
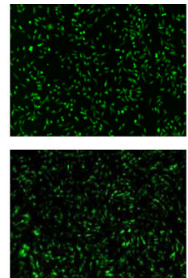

PCNP
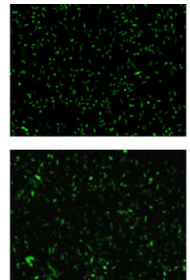

sh-Scb
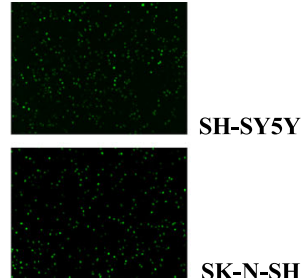

sh-PCNP

b

\section{SH-SY5Y}

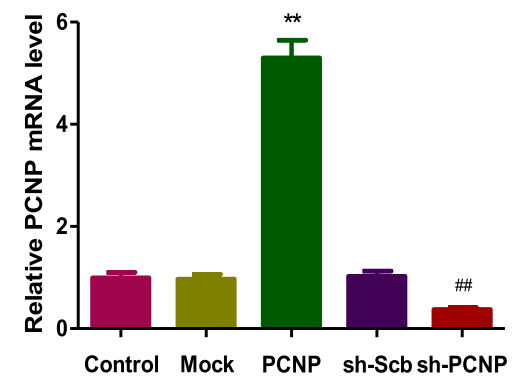

C

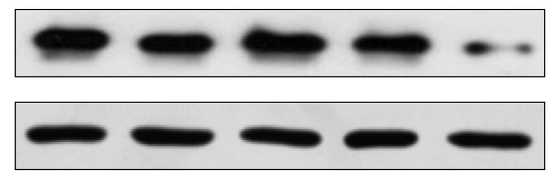

Control Mock PCNP sh-Scb sh-PCNP
SK-N-SH

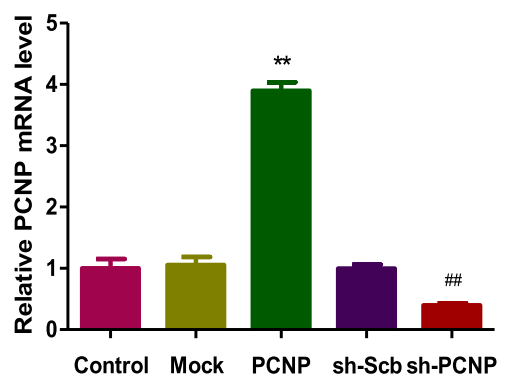

SK-N-SH

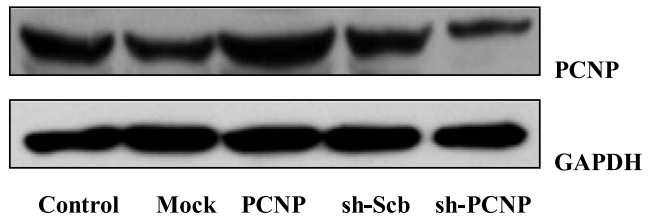

SK-N-SH

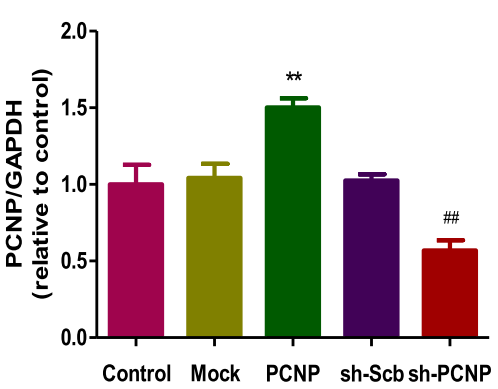

Fig. 1 Over-expression and down-regulation of PCNP in human neuroblastoma cells. a Fluorescence microscopy of PCNP in SH-SY5Y and SK-NSH cells; original magnification $100 \times$. b The expression level of PCNP mRNA was examined by RT-PCR. $\mathbf{c}$ The protein expression of PCNP was examined by Western blotting. GAPDH was used as the loading control. $\mathbf{d}$ The densitometry analysis of PCNP was performed, normalized to the corresponding GAPDH level. Data are presented as mean \pm SEM of three independent experiments; ${ }^{*} P<0.05$, ${ }^{* *} P<0.01$ compared with the Mock group; ${ }^{\#} P<0.05,{ }^{\# \#} P<0.01$ compared with the sh-Scb group

Bax/Bcl-2 and Bad/Bcl-xl ratios are common phenomena in mitochondrial apoptosis [26, 27]. As shown in Fig. 5, Bax/Bcl-2 and Bad/Bcl-xl ratios increased in the PCNP group compared with the Mock group and decreased in the sh-PCNP group compared with the shScb group.
PCNP mediates the mitogen-activated protein kinase (MAPK) pathway in human neuroblastoma cells

MAPK signaling pathway plays a key role in the regulation of many cellular processes, including cell proliferation, differentiation, and apoptosis [28]. The MAPK family is composed of three major components: ERK1/2, 


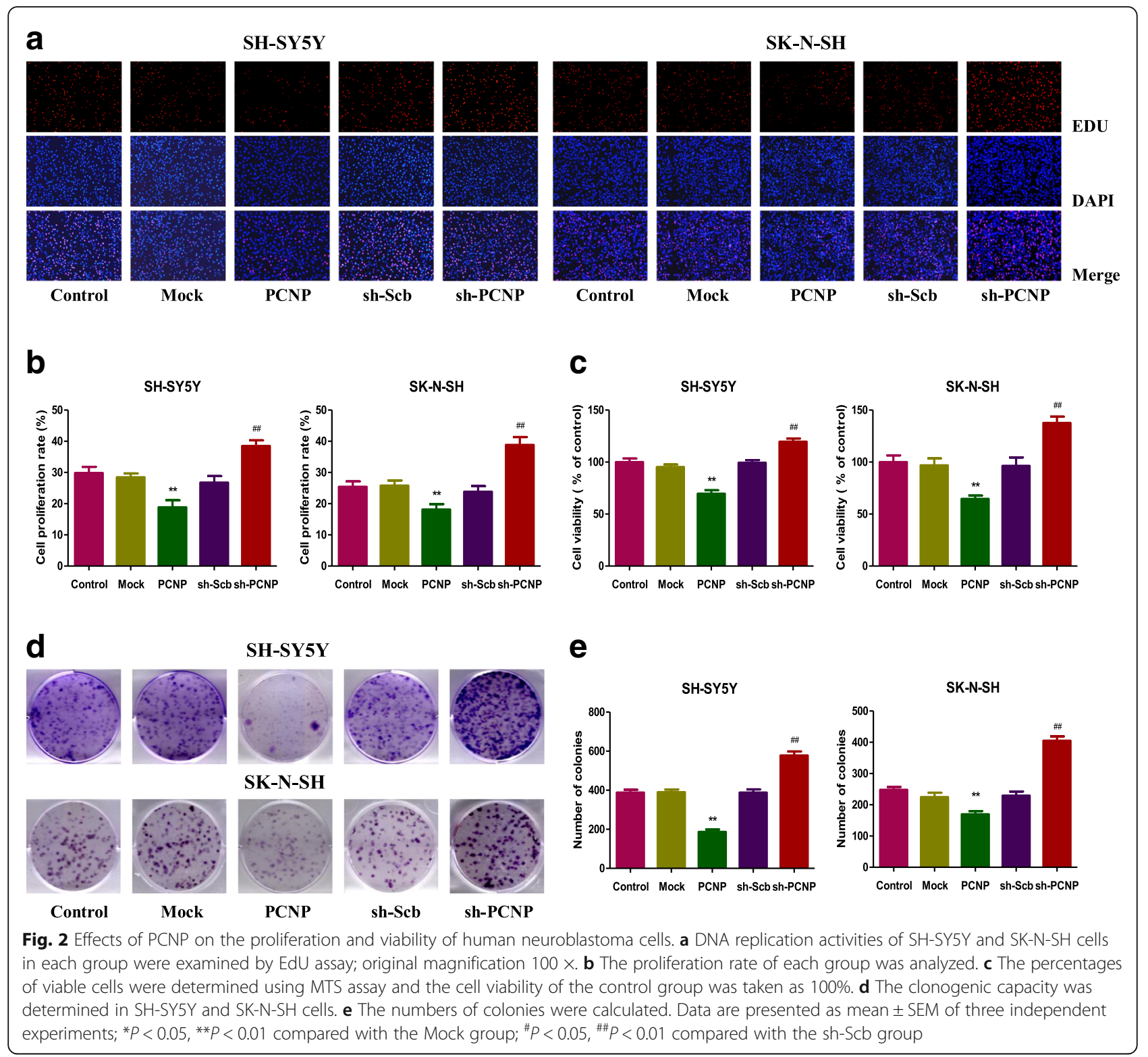

JNK, and p38 protein kinases [29, 30]. As shown in Fig. 6 , PCNP over-expression triggered phosphorylations of p38 (Thr180/Tyr182), JNK (Thr183/Tyr185), and ERK1/2 (Thr202/Tyr204) with distinct patterns. However, PCNP knockdown significantly decreased phosphorylations of these protein kinases. The results show that PCNP mediates the MAPK signaling pathway in human neuroblastoma cells.

\section{PCNP mediates the PI3K/AKT/mTOR pathway in human neuroblastoma cells}

The PI3K/Akt/mTOR cascade is an important signal transduction pathway involved in most hallmarks of cancer: cell survival, motility, metabolism, and genomic instability $[31,32]$. The pathway contributes to cancer- promoting aspects of the tumor environment, including angiogenesis and inflammatory cell recruitment [31]. As shown in Fig. 7, phosphorylations of PI3K (Tyr458/ Tyr199), AKT (Ser473), and mTOR (Ser2448) decreased in the PCNP group and increased in the sh-PCNP group, suggesting that PCNP mediates the PI3K/AKT/ mTOR signaling pathway in human neuroblastoma cells.

PCNP regulates the growth and angiogenesis of human neuroblastoma xenograft tumors in nude mice SH-SY5Y and SK-N-SH cells have been widely used to establish subcutaneous xenograft models [33-35]. Then the effect of PCNP on the growth of neuroblastoma xenograft tumors was detected. PCNP over-expression decreased the growth of xenograft tumors, when 
a

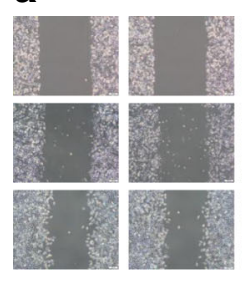

SH-SY5Y
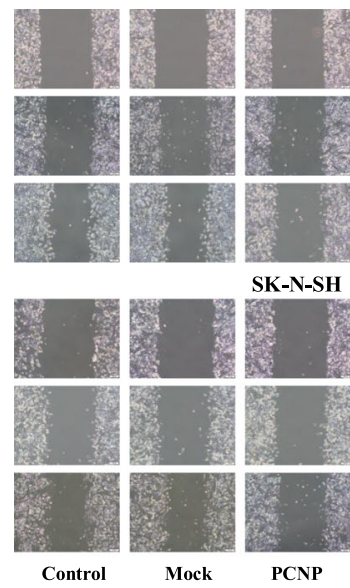

SK-N-SH

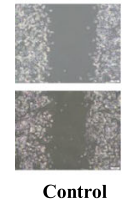

c

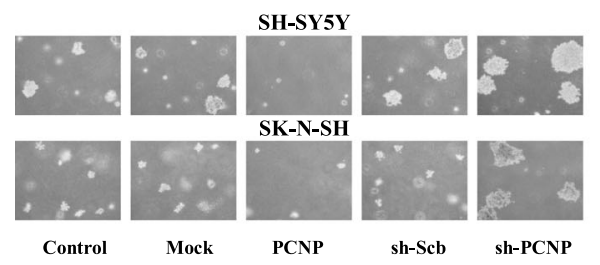

e

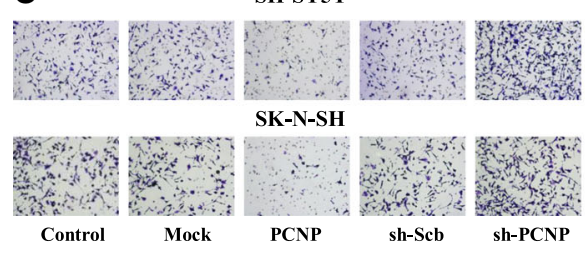

g

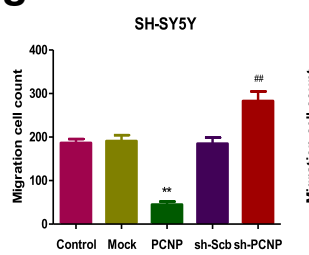

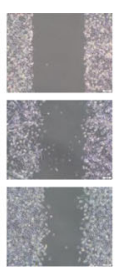
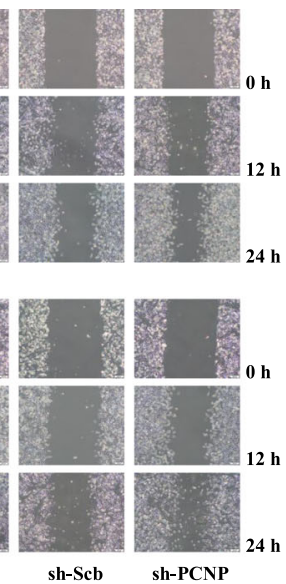

b

.

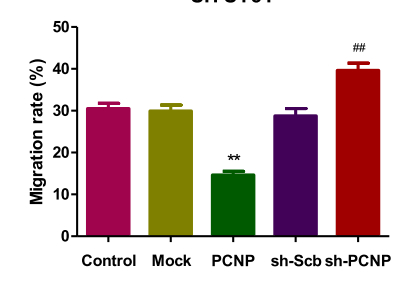

SK-N-SH

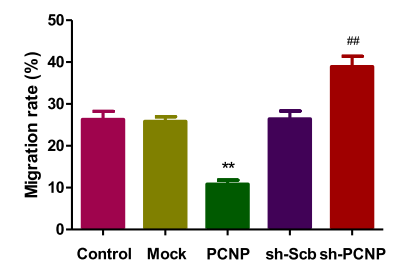

d

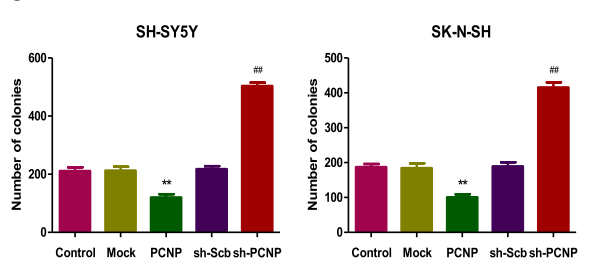

$f$

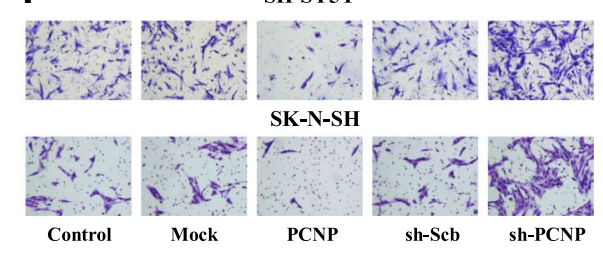

h

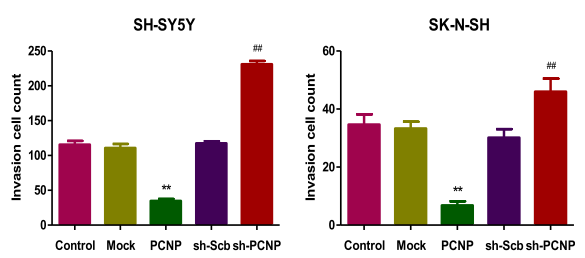

Fig. 3 Effects of PCNP on the migration and invasion of human neuroblastoma cells. a The effect of PCNP on cell migration was measured by wound healing assay; original magnification $100 \times$. b Soft agar assay was performed to examine the anchorage-independent survival of cells; original magnification $100 \times$. c The migration rates of SH-SY5Y and SK-N-SH cells were calculated by the formula shown above. $\mathbf{d}$ The number of colonies was calculated. e Transwell assay was performed to assess the migration of SH-SY5Y and SK-N-SH cells; original magnification $200 \times$. $\mathbf{f}$ Transwell assay was performed to assess the invasion of SH-SY5Y and SK-N-SH cells; original magnification $200 \times . \mathbf{g}$ The numbers of the migrated cells were calculated. $\mathbf{h}$ The numbers of the invasive cells were calculated. Data are presented as mean \pm SEM of three independent experiments; ${ }^{*} P<0.05$, ${ }^{* *} P<0.01$ compared with the Mock group; ${ }^{\#} P<0.05,{ }^{\# \#} P<0.01$ compared with the sh-Scb group

compared to the Mock group. However, PCNP knockdown increased the growth of xenograft tumors compared with the sh-Scb group (Fig. 8a-e). Furthermore, there was no significant difference in body weight between each group (Fig. 8f and g). IHC with the Ki67 antibody confirmed that the in vivo proliferation of neuroblastoma cells was inhibited in the PCNP group compared with the Mock group and promoted in the sh-PCNP group compared with the sh-Scb group. Moreover, the protein expression of CD31 in neuroblastoma xenograft tumors exhibited a similar trend (Fig. 9). These results together indicate that PCNP 
a
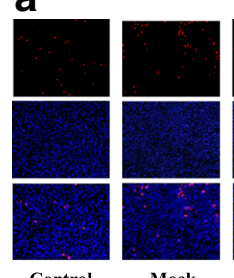

b

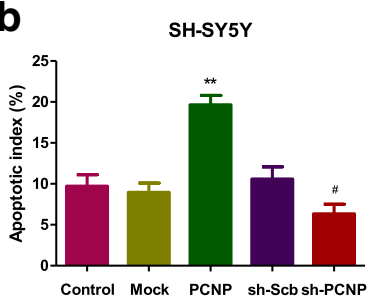

C
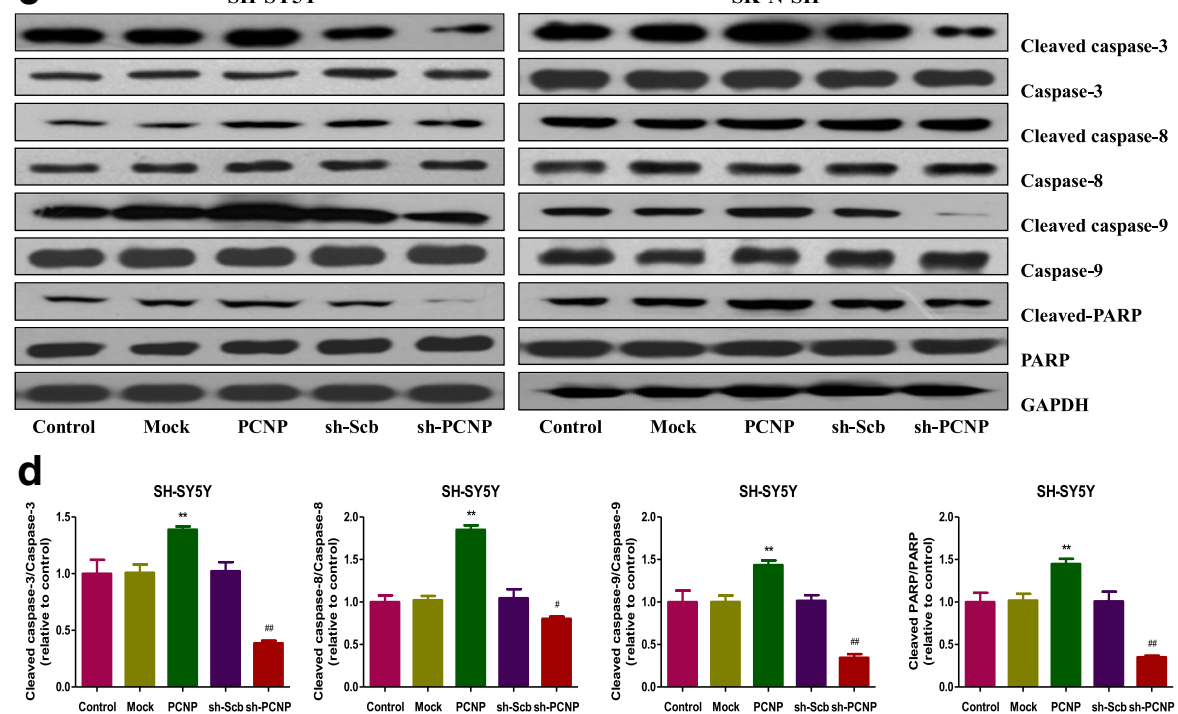

e
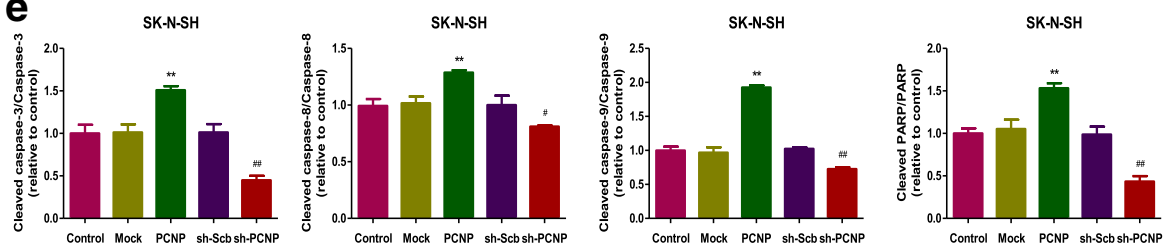

Fig. 4 Effects of PCNP on the apoptosis of human neuroblastoma cells. a The apoptotic levels of SH-SY5Y and SK-N-SH cells were measured by TUNEL staining; original magnification 100x. $\mathbf{b}$ The percentages of TUNEL-positive cells were calculated by the formula shown above. $\mathbf{c}$ Western blotting analysis for the expression of cleaved caspase-3, -8 , and -9 and cleaved PARP in SH-SY5Y and SK-N-SH cells. GAPDH was used as the loading control. (d, e) The densitometry analysis of each factor was performed in SH-SY5Y and SK-N-SH cells, normalized to the corresponding GAPDH level. Data are presented as mean \pm SEM of three independent experiments; ${ }^{*} P<0.05,{ }^{* *} P<0.01$ compared with the Mock group; ${ }^{\#} P<0.05$, \#\# $P$ 0.01 compared with the sh-Scb group

could modulate the growth and angiogenesis of human neuroblastoma xenograft tumors.

\section{Discussion}

PCNP is a novel nuclear protein that could interact with NIRF and modulate the transcriptional activity of NIRF
[18]. Recent studies suggest that PCNP may play an important role in cell proliferation and tumorigenesis $[18,19]$. However, the precise mechanism of action of PCNP in the proliferation, migration, and invasion of cancer cells has not yet been fully elucidated. The human neuroblastoma cell lines SH-SY5Y and SK-N-SH possess several properties 

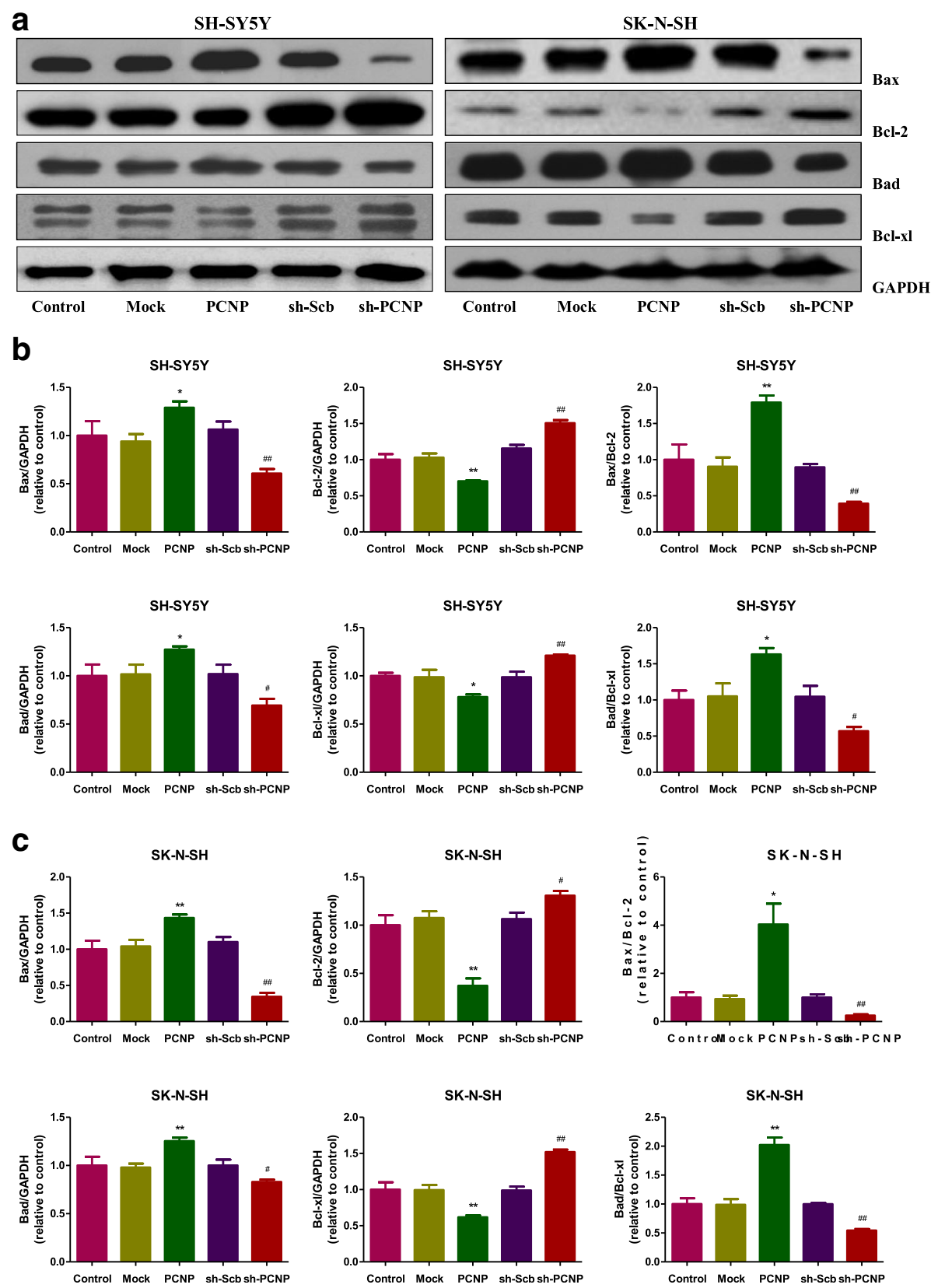

Fig. 5 Effects of PCNP on the expressions of $\mathrm{BCl}-2$ family proteins in human neuroblastoma cells. a Western blotting analysis of the expressions of Bax, BCl-2, Bad, and BCl-xl in SH-SY5Y and SK-N-SH cells. GAPDH was used as the loading control. (b, c) The densitometry analysis of each factor was performed, normalized to the corresponding GAPDH level. The expression ratios of Bax/BCl-2 and Bad/BCl-xL were quantified. Data are presented as mean \pm SEM of three independent experiments; ${ }^{*} P<0.05$, ${ }^{* *} P<0.01$ compared with the Mock group; ${ }^{\#} P<0.05$, ${ }^{\# \#} P<0.01$ compared with the sh-Scb group

of neuronal cells and have been widely used as cellular models to investigate the intracellular mechanisms of action of therapeutic agents [36]. In the present study, SHSY5Y and SK-N-SH cells were used to evaluate the effects of PCNP in vitro and in vivo. The results demonstrated that the expression of PCNP can be detected in human neuroblastoma cells, in addition to fibrosarcoma cells, hepatoma cells, and myeloid leukemia cells [18]. PCNP over- expression attenuated the proliferation and viability, as well as decreased the migration and invasion capabilities of $\mathrm{SH}-$ SY5Y and SK-N-SH cells, whereas PCNP knockdown exhibited completely opposite effects, suggesting that PCNP could play important roles in the growth, migration, and invasion of human neuroblastoma cells.

Apoptosis, also known as programmed cell death, is a critical process for the normal development and 

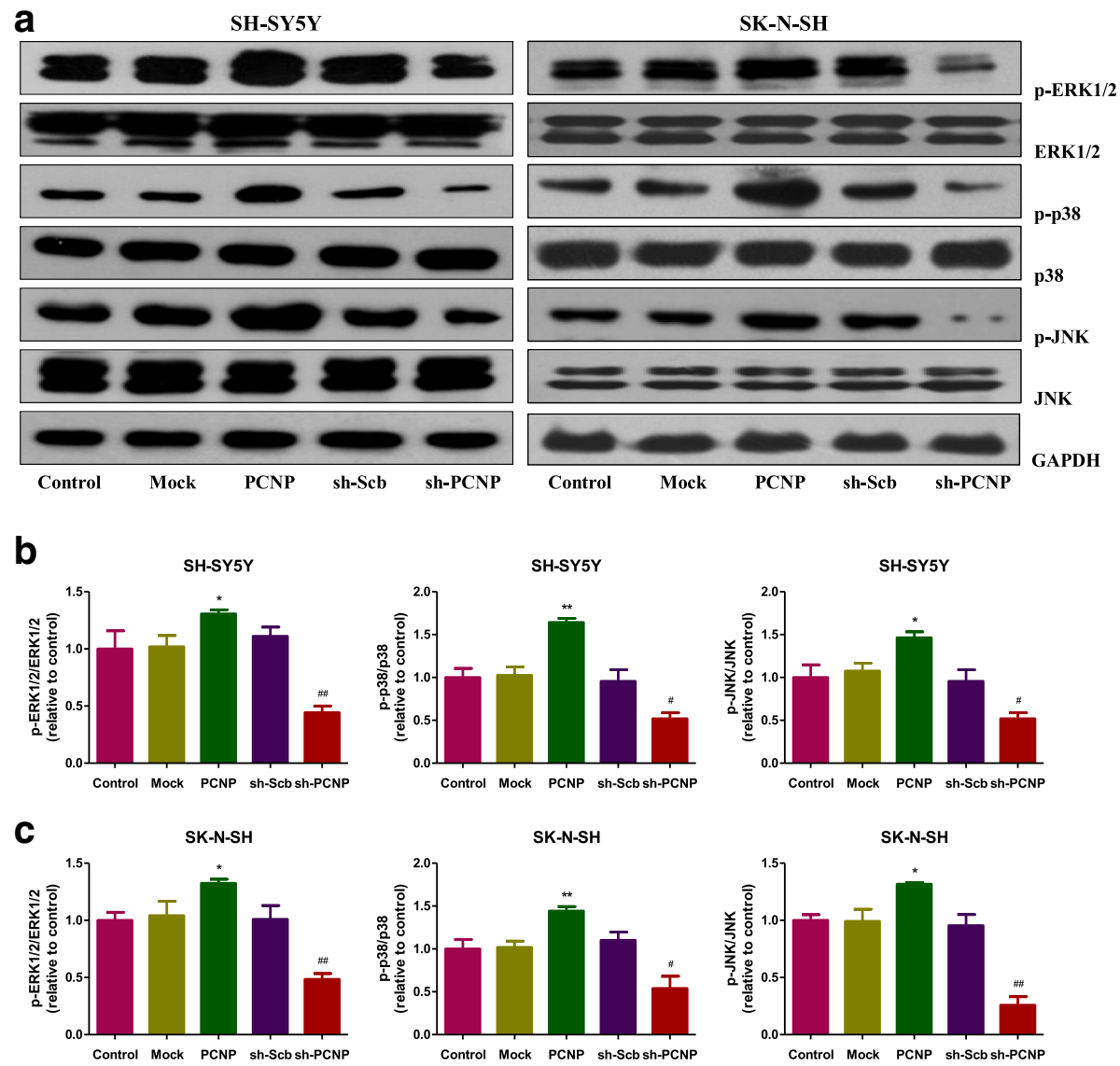

Fig. 6 PCNP mediates the MAPK pathway in human neuroblastoma cells. a Western blotting analysis of the expressions of ERK1/2, ERK1/2 (Thr202/Tyr204), p38, p38 (Thr180/Tyr182), JNK, and p-JNK (Thr183/Tyr185) in SH-SY5Y and SK-N-SH cells. GAPDH was used as the loading control. b, c The intensities of the bands were quantified by densitometry analyses and normalized by the amount of ERK, p38, or JNK. Data are presented as mean \pm SEM of three independent experiments; ${ }^{*} P<0.05$, ${ }^{*} P<0.01$ compared with the Mock group; ${ }^{*} P<0.05$, ${ }^{\# \#} P<0.01$ compared with the sh-Scb group

maintenance of tissue homeostasis in multicellular organisms [37]. There are two apoptotic signaling pathways: an intrinsic pathway that occurs through the mitochondria and an extrinsic pathway initiated by death receptors [38]. The Bcl-2 family of proteins, such as Bax, $\mathrm{Bcl}-2, \mathrm{Bad}$, and $\mathrm{Bcl}-\mathrm{xl}$, could function as central regulators of apoptosis in mammals [39]. Caspases could be activated in response to apoptotic stimuli and cleaved caspase- 3 could inactivate PARP, thus eventually resulting in the occurrence of apoptotic cascade [40]. Our results showed that PCNP over-expression remarkably increased the apoptotic index, protein expressions of cleaved caspase- $3,8,9$, as well as $\mathrm{Bax} / \mathrm{Bcl}-2$ and $\mathrm{Bad} /$ $\mathrm{Bcl}-\mathrm{xl}$ ratios, suggesting the activation of mitochondriamediated pathway. However, PCNP knockdown dramatically decreased the level of apoptosis, indicating that PCNP has pro-apoptotic function in neuroblastoma.

MAPKs regulate a variety of cellular events, including proliferation, differentiation, and apoptosis, and three major MAPK subfamilies have been identified, ERK 1/2, p38, and JNK [28-30]. Increased expression of p-ERK has been found in many cancers, which can induce cancer cell proliferation and cancer progression [41]. However, many studies have shown that increased p-ERK could promote the apoptosis process in SH-SY5Y cells [42-44]. These controversial results may be attributed to the differences in cell lines [45]. Furthermore, p38 and JNK can be phosphorylated in rotenone-induced apoptosis in SH-SY5Y cells [46]. Our results indicated that PCNP over-expression could induce apoptosis by triggering phosphorylations of p38 (Thr180/Tyr182), JNK (Thr183/Tyr185), and ERK1/2 (Thr202/Tyr204) in both SH-SY5Y and SK-NSH cells. However, PCNP knockdown could promote the growth, migration, and invasion of neuroblastoma cells by decreasing phosphorylations of p38 (Thr180/ Tyr182), JNK (Thr183/Tyr185), and ERK1/2 (Thr202/ Tyr204). These results together suggest that PCNP can regulate the growth process of human neuroblastoma cells via the MAPK signaling pathway.

The PI3K/Akt/mTOR signaling pathway plays important roles in promoting cell survival, growth, 

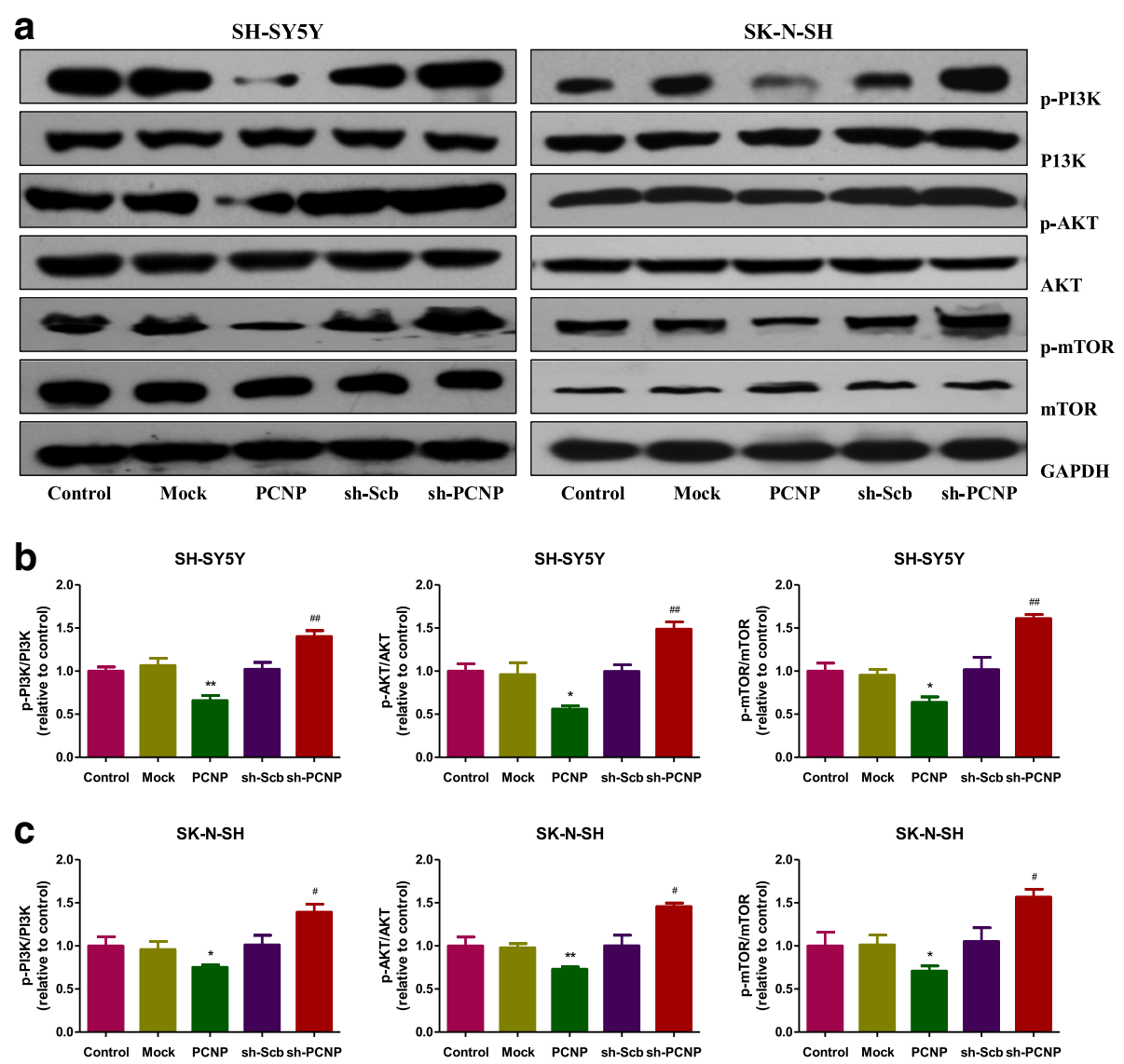

Fig. 7 PCNP mediates the PI3K/AKT/mTOR pathway in human neuroblastoma cells. a Western blotting analysis of the expressions of PI3K, p-PI3K (Tyr458/ Tyr199), AKT, p-AKT (Ser473), mTOR, and p-mTOR (Ser2448) in SH-SY5Y and SK-N-SH cells. GAPDH was used as the loading control. b, c The intensities of the bands were quantified by densitometry analyses and normalized by the amount of PI3K, AKT, or mTOR. Data are presented as mean \pm SEM of three independent experiments; ${ }^{*} P<0.05$, ${ }^{* *} P<0.01$ compared with the Mock group; ${ }^{\#} P<0.05$, ${ }^{\# \#} P<0.01$ compared with the sh-Scb group

motility, and protein synthesis [32, 47, 48]. PI3K activates the serine/threonine kinase Akt, which in turn phosphorylates and activates mTOR through a cascade of regulators [47]. Activation of the PI3K/AKT/ mTOR pathway is involved in tumor progression and reduced patient survival [49]. It has been widely accepted that PI3K/AKT/mTOR pathway is a promising therapeutic target for the treatment of cancer [32, 47, 50]. A recent study indicates that alectinib could suppress cell proliferation and induce apoptosis through the inhibition of PI3K/Akt/mTOR signaling in neuroblastoma cells [51]. Moreover, afatinib exhibits antitumor efficacy by inducing apoptosis and blocking the $\mathrm{PI} 3 \mathrm{~K} / \mathrm{AKT} / \mathrm{mTOR}$ signaling in a neuroblastoma xenograft mouse model [52]. Similarly, our results showed that PCNP over-expression significantly induced apoptosis by inhibiting phosphorylations of PI3K (Tyr458/ Tyr199), AKT (Ser473), and mTOR (Ser2448), suggesting that PCNP-associated agents can be developed as anti-cancer drugs. Nevertheless, PCNP knockdown promoted the growth, migration, and invasion of neuroblastoma cells via increasing phosphorylations of PI3K (Tyr458/Tyr199), AKT (Ser473), and mTOR (Ser2448). These data reveal that PCNP can regulate the growth, migration, and invasion of human neuroblastoma cells through the PI3K/Akt/mTOR signaling pathway.

A number of studies indicate that SH-SY5Y and SK$\mathrm{N}-\mathrm{SH}$ cells have been widely adopted to establish subcutaneous xenograft models [33-35]. We therefore examined the effect of PCNP on the growth of neuroblastoma xenograft tumors in BALB/c nude mice. PCNP over-expression significantly decreased the growth of neuroblastoma xenograft tumors, whereas PCNP knockdown notably promoted tumor growth. However, the tumor inhibitory rate of PCNP in $\mathrm{SH}$ SY5Y cells was higher than that in SK-N-SH cells, which can be attributed to the difference of the level of GD2 ganglioside expression between SH-SY5Y and SK-N-SH cells [53, 54]. Ki67, a nuclear non-histone protein, can be detected in proliferating cells in all stages of the cell cycle except G0 [55]. The expression 
a

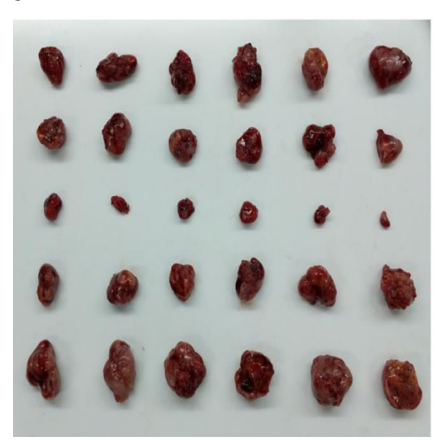

b

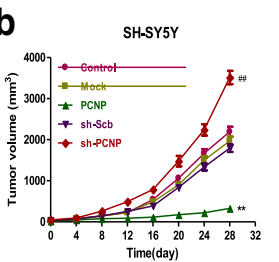

d
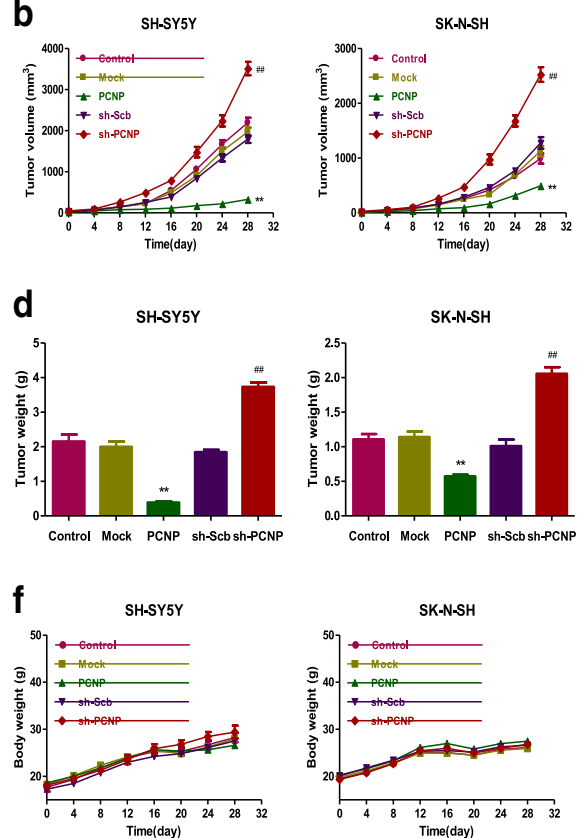
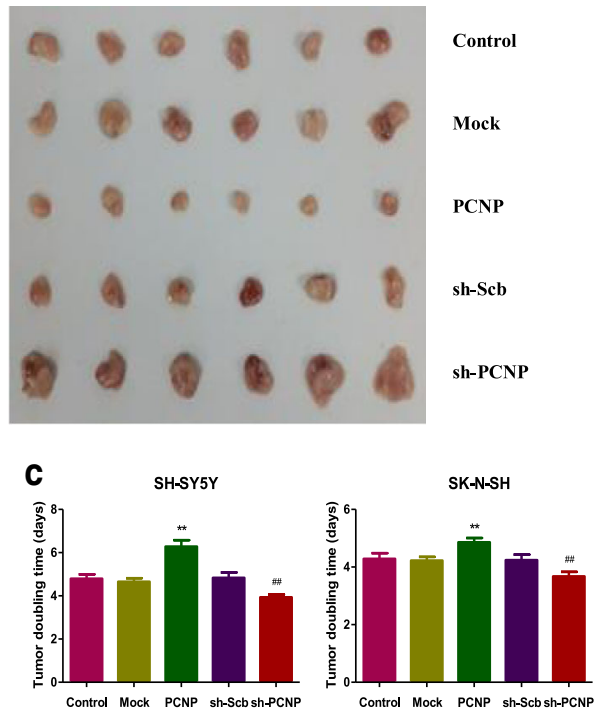

C

e
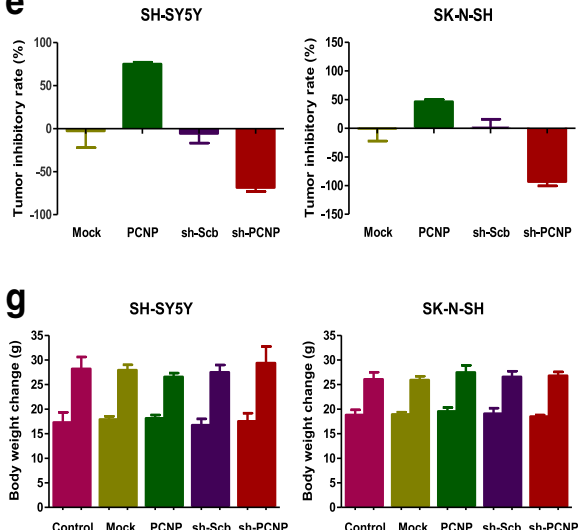

Fig. 8 Effects of PCNP on the growth of SH-SY5Y and SK-N-SH xenograft tumors in nude mice. a Representative xenografts dissected from different groups of nude mice were shown. (b, c) The tumor volume of each group was measured every day and the TVDT was calculated by the formula shown above. (d, e) The tumors were weighed and the inhibition rates of tumor growth were calculated by the formula shown above. (f, $\mathbf{g})$ The body weight change curve of each group during the experiment and the body weight of each group on the first day (day 0) and the last day (day 28). Values are presented as mean $\pm \operatorname{SEM}(n=6) ;{ }^{*} P<0.05$, ${ }^{* *} P<0.01$ compared with the Mock group; ${ }^{\#} P<0.05,{ }^{\# \#} P<0.01$ compared with the sh-Scb group

of Ki67 closely associates with the proliferation, invasiveness, and clinical outcome of a variety of malignant tumors [56]. Ki67 is considered an important marker and has been widely used in detecting the proliferation of malignant cells $[23,55,56]$. The results showed that the expression of Ki67 was decreased in the PCNP group and increased in the shPCNP group, which was in good agreement with the above findings. CD31 is an ideal biomarker for vascular endothelial cells and its density is represented by the tumor MVD [24, 25]. The results indicated that PCNP over-expression reduced the expression of CD31, while PCNP knockdown promoted the expression of CD31 in neuroblastoma xenograft tumors, suggesting that PCNP could modulate the growth of human neuroblastoma xenograft tumors by regulating angiogenesis.

\section{Conclusions}

We demonstrate that the expression of PCNP can be detected in human neuroblastoma cells. The study suggests that PCNP could mediate the proliferation, migration, and invasion of human neuroblastoma cells through MAPK and PI3K/AKT/mTOR signaling pathways. Considering its importance in the developmental process of human neuroblastoma cells, PCNP could be a potential therapeutic target for advanced and recurrent human neuroblastoma. The finding that over-expression of PCNP reduces the growth of human neuroblastoma xenograft tumors by regulating angiogenesis makes PCNP a potential therapeutic target. 
a

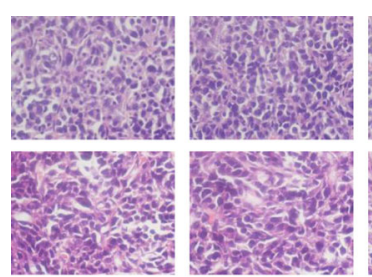

Control

b
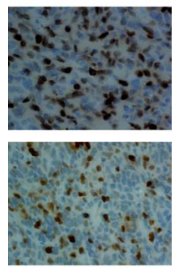

Control

C

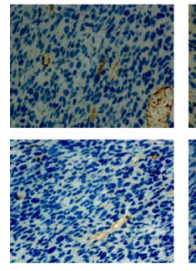

Control

Mock
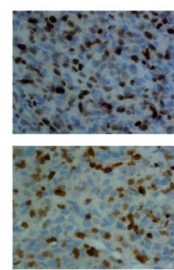

Mock d

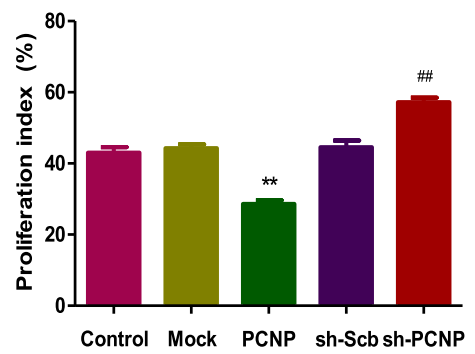

e

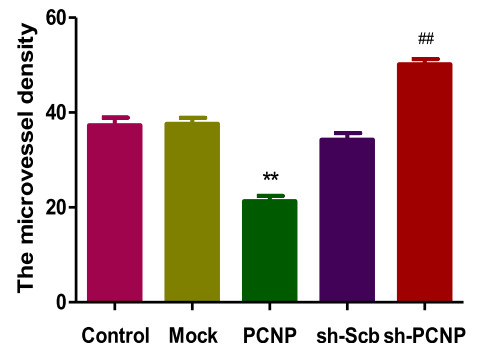

Ki67

CD31
HE

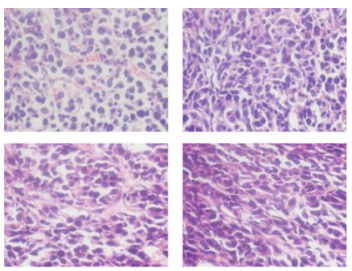

sh-Scb

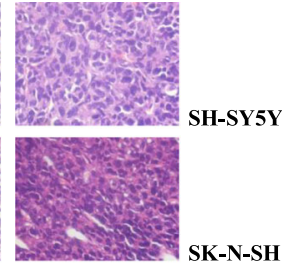

sh-PCNP

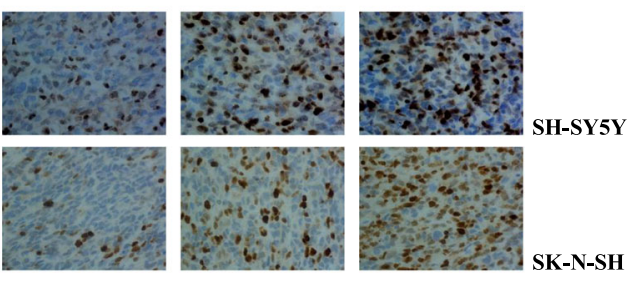

sh-PCNP

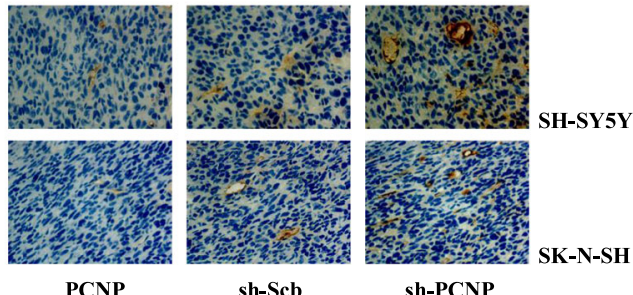

SK-N-SH

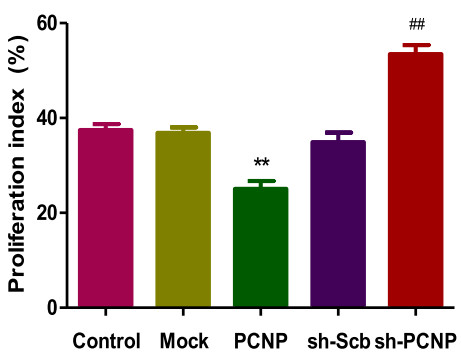

SK-N-SH

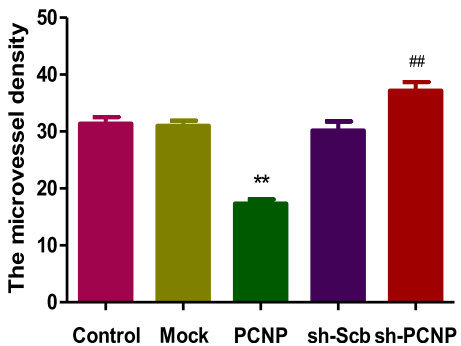

Fig. 9 Effects of PCNP on the PI and MVD of human neuroblastoma xenografts. (a, b, c) Representive photographs of HE, Ki67, and CD31 staining in SH-SY5Y and SK-N-SH xenograft tumors; original magnification 400x. (d, e, f) The PI and MVD were calculated by the formula shown above. Values are presented as mean \pm SEM $(n=6) ;{ }^{*} P<0.05,{ }^{*} P<0.01$ compared with the Mock group; ${ }^{\#} P<0.05,{ }^{\# \#} P<0.01$ compared with the sh-Scb group 


\section{Abbreviations}

Bad: BCl-xl/BCl-2-associated death promoter; Bax: Bcl-2-associated X protein; BCl-2: B-cell lymphoma-2; BCl-xl: B-cell lymphoma-extra large; CD31: Cluster of differentiation 31; cDNA: Complementary deoxyribonucleic acid; DAPI: 4', 6diamidino-2-phenylindole; E: Glutamic acid; EdU: 5-ethynyl-2'-deoxyuridine; ERK1/2: extracellular signal-regulated protein kinase 1/2; FBS: Fetal bovine serum; GAPDH: Glyceraldehyde-3-phosphate dehydrogenase; HE: Hematoxylin and eosin; IHC: Immunohistochemistry; IR: Inhibition rate; JNK: c-Jun N-terminal kinase; MAPK: Mitogen-activated protein kinase; MR: Migration rate; mTOR: mammalian target of rapamycin; MVD: Microvessel density; NIRF: Np95/ICBP90-like RING finger protein; P: Proline; PARP: Poly adenosine diphosphate-ribose polymerase; PBS: Phosphate-buffered saline; PCNP: PEST-containing nuclear protein; Pl: Proliferation index; PI3K: phosphatidylinositol 3-kinase; RT-PCR: Reverse transcription-polymerase chain reaction; S: Serine; shRNA: Short hairpin ribonucleic acid; T: Threonine; TUNEL: TdT-mediated dUTP-biotin nick end labeling; TVDT: Tumor volume doubling time

\section{Funding}

This work was supported by grants from the National Natural Science Foundation of China (Nos. U1504817, 81670088), the Foundation of Science \& Technology Department of Henan Province, China (Nos. 182102310335, 172102410019), the Natural Science Foundation of Education Department of Henan Province, China (No. 15A310017), and the Science Foundation of Henan University, China (Nos. yqpy20170044, 16NB048). Funding bodies did not have any influence in the design of the study and collection, analysis, and interpretation of data or in writing the manuscript.

\section{Availability of data and materials}

All data generated or analyzed during this study are included in this article and further information available from the corresponding author on reasonable request.

\section{Authors' contributions}

$X Y J, J S W$ and DDW conceived the study and drafted the manuscript. DDW, YRG, TL, DYW, DL, SYL, YH, HBN, JPL, JS and JFS designed and performed the experiments. DDW, YRG and TL analyzed the data and prepared the figures. All authors read and approved the final manuscript.

\section{Ethics approva}

Animal experiments were approved by the Committee of Medical Ethics and Welfare for Experimental Animals of Henan University School of Medicine (HUSOM-2017-196) in compliance with the Experimental Animal Regulations formulated by the National Science and Technology Commission, China.

\section{Competing interests}

The authors declare that they have no competing interests.

\section{Publisher's Note}

Springer Nature remains neutral with regard to jurisdictional claims in published maps and institutional affiliations.

\section{Author details \\ ${ }^{1}$ School of Basic Medical Sciences, Henan University College of Medicine, Kaifeng 475004, Henan, China. ${ }^{2}$ Henan Provincial People's Hospital Affiliated to Henan University, Zhengzhou 450003, Henan, China. ${ }^{3}$ Brain Research Laboratory, College of Life Sciences, Henan University, Kaifeng 475004, Henan, China. ${ }^{4}$ Nanyang Nanshi Hospital Affiliated to Henan University, Nanyang 473003, Henan, China.}

Received: 4 October 2017 Accepted: 17 April 2018

Published online: 02 May 2018

\section{References}

1. Diskin SJ, Hou C, Glessner JT, Attiyeh EF, Laudenslager M, Bosse K, et al. Copy number variation at 1q21.1 associated with neuroblastoma. Nature. 2009;459:987-91.

2. Brodeur GM, Bagatell R. Mechanisms of neuroblastoma regression. Nat Rev Clin Oncol. 2014;11:704-13.
3. Capasso M, Devoto M, Hou C, Asgharzadeh S, Glessner JT, Attiyeh EF, et al. Common variations in BARD1 influence susceptibility to high-risk neuroblastoma. Nat Genet. 2009;41:718-23.

4. Maris JM. Recent advances in neuroblastoma. N Engl J Med. 2010;362:2202-11.

5. Cheung NK, Dyer MA. Neuroblastoma: developmental biology, cancer genomics and immunotherapy. Nat Rev Cancer. 2013;13:397-411.

6. Valentijn L, Koster J, Haneveld F, Aissa RA, van Sluis P, Broekmans ME, et al. Functional MYCN signature predicts outcome of neuroblastoma irrespective of MYCN amplification. Proc Natl Acad Sci U S A. 2012;109:19190-5.

7. Mossé YP, Laudenslager M, Longo L, Cole KA, Wood A, Attiyeh EF, et al. Identification of ALK as a major familial neuroblastoma predisposition gene. Nature. 2008;455:930-5.

8. Larsson K, Kock A, Idborg H, Arsenian Henriksson M, Martinsson T, Johnsen J, et al. COX/mPGES-1/PGE2 pathway depicts an inflammatory-dependent high-risk neuroblastoma subset. Proc Natl Acad Sci U S A. 2015;112:8070-5.

9. Peifer M, Hertwig F, Roels F, Dreidax D, Gartlgruber M, Menon R, et al. Telomerase activation by genomic rearrangements in high-risk neuroblastoma. Nature. 2015;526:700-4

10. Carpenter EL, Mossé YP. Targeting ALK in neuroblastoma-preclinical and clinical advancements. Nat Rev Clin Oncol. 2012;9:391-9.

11. Chakraborty A, Werner JK Jr, Koldobskiy MA, Mustafa AK, Juluri KR, Pietropaoli J, et al. Casein kinase-2 mediates cell survival through phosphorylation and degradation of inositol hexakisphosphate kinase-2. Pro Natl Acad Sci USA. 2011;108:2205-9.

12. Chapin HC, Caplan MJ. The cell biology of polycystic kidney disease. J Cell Biol. 2010;191:701-10.

13. Agrawal N, Frederick MJ, Pickering CR, Bettegowda C, Chang K, Li RJ, et al. Exome sequencing of head and neck squamous cell carcinoma reveals inactivating mutations in NOTCH1. Science. 2011;333:1154-7.

14. Hu H, Zhou Q, Han X, Li Z. CRL4WDR1 controls polo-like kinase protein abundance to promote bilobe duplication, basal body segregation and flagellum attachment in Trypanosoma brucei. PLoS Pathog. 2017;13: e1006146.

15. Xu Y, Sun Y, Ye H, Zhu L, Liu J, Wu X, et al. Increased dysbindin-1B isoform expression in schizophrenia and its propensity in aggresome formation. Cell Discov. 2015:1:15032.

16. Yada M, Hatakeyama S, Kamura T, Nishiyama M, Tsunematsu R, Imaki H, et al. Phosphorylation-dependent degradation of c-Myc is mediated by the F-box protein Fbw7. EMBO J. 2004;23:2116-25.

17. Meyer RD, Srinivasan S, Singh AJ, Mahoney JE, Gharahassanlou KR, Rahimi N PEST motif serine and tyrosine phosphorylation controls vascular endothelial growth factor receptor 2 stability and downregulation. Mol Cell Biol. 2011;31:2010-25

18. Mori T, Li Y, Hata H, Ono K, Kochi H. NIRF, a novel RING finger protein, is involved in cell-cycle regulation. Biochem Biophys Res Commun. 2002;296: 530-6.

19. Mori T, Li Y, Hata H, Kochi H. NIRF is a ubiquitin ligase that is capable of ubiquitinating PCNP, a PEST-containing nuclearprotein. FEBS Lett. 2004;557: 209-14

20. Wu D, Luo N, Wang L, Zhao Z, Bu H, Xu G, et al. Hydrogen sulfide ameliorates chronic renal failure in rats by inhibiting apoptosis and inflammation through ROS/MAPK and NF-KB signaling pathways. Sci Rep. 2017;7:455.

21. Wu D, Gao Y, Chen L, Qi Y, Kang Q, Wang H, et al. Anti-tumor effects of a novel chimeric peptide on $\mathrm{S} 180$ and $\mathrm{H} 22$ xenografts bearing nude mice. Peptides. 2010;31:850-64.

22. Heilmann AM, Perera RM, Ecker $\mathrm{V}$, Nicolay BN, Bardeesy $\mathrm{N}$, Benes $\mathrm{CH}$, et al, CDK4/6 and IGF1 receptor inhibitors synergize to suppress the growth of p16INK4A-deficient pancreatic cancers. Cancer Res. 2014;74:3947-58.

23. Ellingson BM, Nguyen HN, Lai A, Nechifor RE, Zaw O, Pope WB, et al. Contrast-enhancing tumor growth dynamics of preoperative, treatmentnaive human glioblastoma. Cancer. 2016;122:1718-27.

24. Keam B, Im SA, Lee KH, Han SW, Oh DY, Kim JH, et al. Ki-67 can be used for further classification of triple negative breast cancer into two subtypes with different response and prognosis. Breast Cancer Res. 2011;13:R22.

25. Tolaney SM, Boucher Y, Duda DG, Martin JD, Seano G, Ancukiewicz M, et al. Role of vascular density and normalization in response to neoadjuvant bevacizumab and chemotherapy in breast cancer patients. Proc Natl Acad Sci U S A. 2015;112:14325-30.

26. Pitchakarn P, Suzuki S, Ogawa K, Pompimon W, Takahashi S, Asamoto M, et al. Induction of G1 arrest and apoptosis in androgen-dependent human 
prostate cancer by Kuguacin J, a triterpenoid from Momordica charantia leaf. Cancer Lett. 2011;306:142-50.

27. Chen M, Wang X, Zha D, Cai F, Zhang W, He Y, et al. Apigenin potentiates TRAIL therapy of non-small cell lung cancer via upregulating DR4/DR5 expression in a p53-dependent manner. Sci Rep. 2016;6:35468.

28. Wagner EF, Nebreda AR. Signal integration by JNK and p38 MAPK pathways in cancer development. Nat Rev Cancer. 2009;9:537-49.

29. Johnson GL, Lapadat R. Mitogen-activated protein kinase pathways mediated by ERK, JNK, and p38 protein kinases. Science. 2002;298:1911-2.

30. Liu X, Ma B, Malik AB, Tang H, Yang T, Sun B, et al. Bidirectional regulation of neutrophil migration by mitogen-activated protein kinases. Nat Immunol. 2012;13:457-64.

31. Fruman DA, Rommel C. PI3K and cancer: lessons, challenges and opportunities. Nat Rev Drug Discov. 2014;13:140-56.

32. Bressanin D, Evangelisti C, Ricci F, Tabellini G, Chiarini F, Tazzari PL, et al. Harnessing the PI3KJAkt/mTOR pathway in T-cell acute lymphoblastic leukemia: eliminating activity by targeting at different levels. Oncotarget 2012;3:811-23.

33. Zhang H, Pu J, Qi T, Qi M, Yang C, Li S, et al. MicroRNA-145 inhibits the growth, invasion, metastasis and angiogenesis of neuroblastoma cells through targeting hypoxia-inducible factor 2 alpha. Oncogene. 2014;33:387-97.

34. Wang Y, Wang L, Guan S, Cao W, Wang H, Chen Z, et al. Novel ALK inhibitor AZD3463 inhibits neuroblastoma growth by overcoming crizotinib resistance and inducing apoptosis. Sci Rep. 2016;6:19423.

35. Ham J, Costa C, Sano R, Lochmann TL, Sennott EM, Patel NU, et al. Exploitation of the apoptosis-primed state of MYCN-amplified neuroblastoma to develop a potent and specific targeted therapy combination. Cancer Cell. 2016;29:159-72.

36. Dedoni $\mathrm{S}$, Olianas MC, Onali P. Interferon- $\beta$ induces apoptosis in human $\mathrm{SH}$ SY5Y neuroblastoma cells through activation of JAK-STAT signaling and down-regulation of PI3K/Akt pathway. J Neurochem. 2010;115:1421-33.

37. Wu D, Si W, Wang M, Lv S, Ji A, Li Y. Hydrogen sulfide in cancer: friend or foe? Nitric Oxide. 2015;50:38-45.

38. Wu D, Gao Y, Qi Y, Chen L, Ma Y, Li Y. Peptide-based cancer therapy: opportunity and challenge. Cancer Lett. 2014;351:13-22.

39. Lovell JF, Billen LP, Bindner S, Shamas-Din A, Fradin C, Leber B, et al. Membrane binding by tBid initiates an ordered series of events culminating in membrane permeabilization by Bax. Cell. 2008;135:1074-84.

40. Fan CD, Li Y, Fu XT, Wu QJ, Hou YJ, Yang MF, et al. Reversal of betaamyloid-induced neurotoxicity in PC12 cells by curcumin, the important role of ROS-mediated signaling and ERK pathway. Cell Mol Neurobiol. 2017; 37:211-22.

41. Gao Y, Li J, Qiao N, Meng Q, Zhang M, Wang X, et al. Adrenomedullin blockade suppresses sunitinib-resistant renal cell carcinoma growth by targeting the ERK/MAPK pathway. Oncotarget. 2016;7:63374-87.

42. Kwon SH, Hong SI, Kim JA, Jung YH, Kim SY, Kim HC, et al. The neuroprotective effects of Lonicera japonica THUNB. Against hydrogen peroxide-induced apoptosis via phosphorylation of MAPKs and PI3K/Akt in SH-SY5Y cells. Food Chem Toxicol. 2011;49:1011-9.

43. Kwon SH, Kim JA, Hong SI, Jung YH, Kim HC, Lee SY, et al. Loganin protects against hydrogen peroxide-induced apoptosis by inhibiting phosphorylation of JNK, p38, and ERK 1/2 MAPKs in SH-SY5Y cells. Neurochem Int. 2011;58:533-41.

44. Ki YW, Lee JE, Park JH, Shin IC, Koh HC. Reactive oxygen species and mitogen-activated protein kinase induce apoptotic death of SH-SY5Y cells in response to fipronil. Toxicol Lett. 2012;211:18-28.

45. Liu S, Du F, Li X, Wang M, Duan R, Zhang J, et al. Effects and underlying mechanisms of irisin on the proliferation and apoptosis of pancreatic $\beta$ cells. PLoS One. 2017;12:e0175498.

46. Hu LF, Lu M, Wu ZY, Wong PT, Bian JS. Hydrogen sulfide inhibits rotenoneinduced apoptosis via preservation of mitochondrial function. Mol Pharmacol. 2009;75:27-34.

47. Rodon J, Dienstmann R, Serra V, Tabernero J. Development of PI3K inhibitors: lessons learned from early clinical trials. Nat Rev Clin Oncol. 2013; 10:143-53.

48. Perl A. Activation of mTOR (mechanistic target of rapamycin) in rheumatic diseases. Nat Rev Rheumatol. 2016;12:169-82.

49. Sun $\mathrm{CH}$, Chang $\mathrm{YH}$, Pan CC. Activation of the PI3K/Akt/mTOR pathway correlates with tumour progression and reducedsurvival in patients with urothelial carcinoma of the urinary bladder. Histopathology. 2011;58: 1054-63.
50. Liu Y, Bi T, Wang Z, Wu G, Qian L, Gao Q, et al. Oxymatrine synergistically enhances antitumor activity of oxaliplatin in colon carcinoma through PI3K AKT/mTOR pathway. Apoptosis. 2016;21:1398-407.

51. Lu J, Guan S, Zhao Y, Yu Y, Woodfield SE, Zhang H, et al. The secondgeneration ALK inhibitor alectinib effectively induces apoptosis in humanneuroblastoma cells and inhibits tumor growth in a TH-MYCN transgenic neuroblastoma mousemodel. Cancer Lett. 2017;400:61-8.

52. Mao X, Chen Z, Zhao Y, Yu Y, Guan S, Woodfield SE, et al. Novel multitargeted ErbB family inhibitor afatinib blocks EGF-induced signaling and induces apoptosis in neuroblastoma. Oncotarget. 2017:8:1555-68.

53. Horwacik I, Durbas M, Boratyn E, Wegrzyn P, Rokita H. Targeting GD2 ganglioside and aurora a kinase as a dual strategy leading to cell death in cultures of human neuroblastoma cells. Cancer Lett. 2013;341:248-64.

54. Acosta S, Lavarino C, Paris R, Garcia I, de Torres C, Rodríguez E, et al. Comprehensive characterization of neuroblastoma cell line subtypes reveals bilineage potential similar to neural crest stem cells. BMC Dev Biol. 2009;9:12.

55. Rego MF, Navarrete MA, Facina G, Falzoni R, Silva R, Baracat EC, et al. Analysis of human mammary fibroadenoma by Ki-67 index in the follicular and luteal phases of menstrual cycle. Cell Prolif. 2009;42:241-7.

56. Yerushalmi R, Woods R, Ravdin PM, Hayes MM, Gelmon KA. Ki67 in breast cancer: prognostic and predictive potential. Lancet Oncol. 2010;11:174-83.

\section{Ready to submit your research? Choose BMC and benefit from:}

- fast, convenient online submission

- thorough peer review by experienced researchers in your field

- rapid publication on acceptance

- support for research data, including large and complex data types

- gold Open Access which fosters wider collaboration and increased citations

- maximum visibility for your research: over $100 \mathrm{M}$ website views per year

At BMC, research is always in progress.

Learn more biomedcentral.com/submissions 